\title{
Telmisartan, an AT1 receptor blocker and a PPAR gamma activator, alleviates liver fibrosis induced experimentally by Schistosoma mansoni infection
}

\author{
Yasmeen M Attia ${ }^{1 *}$, Essam F Elalkamy ${ }^{2}$, Olfat A Hammam ${ }^{3}$, Soheir S Mahmoud ${ }^{4}$ and Aiman S El-Khatib ${ }^{5}$
}

\begin{abstract}
Background: Hepatic schistosomiasis is considered to be one of the most prevalent forms of chronic liver disease in the world due to its complication of liver fibrosis. The demonstration of the pro-fibrogenic role of angiotensin (Ang) II in chronic liver disease brought up the idea that anti-Ang II agents may be effective in improving hepatic fibrosis by either blocking Ang II type 1 (AT1) receptors or inhibiting the angiotensin converting enzyme. Peroxisome proliferator-activated receptors gamma (PPARY) activation has been also shown to inhibit hepatic stellate cell activation and progression of fibrosis. The present study has aimed at testing the anti-fibrogenic effects of telmisartan; an AT1 receptor blocker and a PPARY partial agonist, alone or combined with praziquantel (PZQ) on Schistosoma mansoni-induced liver fibrosis in mice.
\end{abstract}

Methods: To achieve the aim of the study, two sets of experiments were performed in which telmisartan was initiated at the $5^{\text {th }}$ (set 1 ) and the $10^{\text {th }}$ (set 2) weeks post infection to assess drug efficacy in both acute and chronic stages of liver fibrosis, respectively. Schistosoma mansoni-infected mice were randomly divided into the following four groups: infected-control (I), telmisartan-treated (II), PZQ-treated (III), and telmisartan+PZQ-treated (IV). In addition, a normal non-infected group was used for comparison. Parasitological (hepatomesenteric worm load and oogram pattern), histopathological, morphometric, immunohistochemical (hepatic expressions of matrix metalloproteinase-2; MMP-2 and tissue inhibitor of metalloproteinase-2; TIMP-2), and biochemical (serum transforming growth factor beta 1; TGF- $\beta 1$ and liver function tests) studies were performed.

Results: Telmisartan failed to improve the parasitological parameters, while it significantly $(P<0.05)$ decreased the mean granuloma diameter, area of fibrosis, and serum TGF- $\beta 1$. Additionally, telmisartan increased MMP-2 and decreased TIMP-2 hepatic expression. Combined treatment failed to show any additive properties, yet it did not affect the anti-schistosomal activity of PZQ.

Conclusions: These results suggest potential anti-fibrotic effects of telmisartan, an AT1 receptor blocker and a PPARy partial agonist, in acute and chronic stages of Schistosoma mansoni-induced liver fibrosis in mice.

Keywords: Hepatic fibrosis, Schistosoma mansoni, Telmisartan, MMP-2, TIMP-2, TGF- $\beta 1$

\footnotetext{
* Correspondence: yasmeen.attia@bue.edu.eg

'Department of Pharmacology and Biochemistry, Faculty of Pharmacy, The British University in Egypt, Suez Desert Road, P.O. Box 43, El Sherouk City,

Cairo 11837, Egypt

Full list of author information is available at the end of the article
} 


\section{Background}

In recent years, there has been an increased recognition of the importance of Neglected Tropical Diseases (NTDs) as impediments to development. The World Health Organization (WHO) has defined seventeen of these conditions as core NTDs [1]. One of these NTDs is schistosomiasis which is a major parasitic disease, caused by blood flukes (trematode worms) of the genus Schistosoma (S.), affecting millions of people worldwide. It is endemic in about 76 countries and territories, though it is estimated that $85 \%$ of the infected people are on the African continent [2]. Chemotherapy with praziquantel (PZQ) is the mainstay of schistosomiasis control. Yet there are recent concerns about tolerance or resistance to $\mathrm{PZQ}$, and hence monitoring its efficacy in different settings is required [3].

Inflammatory hepatic schistosomiasis, which is the main cause of schistosomal hepatomegaly in children and adolescents, is an early reaction to the ova trapped in the perisinusoidal periportal spaces of the liver [4]. Peri-portal fibrosis is considered a serious consequence of $S$. mansoni infection that involves remodeling of extracellular matrix (ECM) and excessive deposition of collagen, primarily by hepatic stellate cells (HSCs), along the branches of the portal tract [5].

Over the last few years, HSCs have been commonly recognized as the principal cell type responsible for ECM protein formation during hepatic fibrogenesis, and the cytokine transforming growth factor beta 1 (TGF- $\beta 1$ ) represents one key factor stimulating collagen and ECM production in these cells [6]. The cytokine TGF- $\beta 1$ promotes wound healing and repair. Under pathological conditions, TGF- $\beta 1$ orchestrates a cross talk between parenchymal, inflammatory, and collagen-expressing cells and plays a key role in stimulating fibrosis. Additionally, overexpression of TGF- $\beta 1$ in transgenic mice results in fibrosis of multiple organs, suggesting that TGF- $\beta 1$ is a major pro-fibrogenic cytokine [7].

Complete recovery from liver fibrosis involves remodelling and breakdown of multiple ECM components, with degradation of the predominant component, collagen I, being particularly important for recovery of normal liver histology. An enlarging family of matrix metalloproteinases (MMPs) was identified, which are calcium-dependent enzymes that specifically degrade collagenous and non-collagenous substrates [8]. Loebermann et al. [9] reported that the expression of MMP-2 correlates with both the onset and progression of fibrosis. However, there is increasing evidence that collagenase inhibition may arise from increased expression of endogenous MMP inhibitors, tissue inhibitor of metalloproteinases (TIMPs) in fibrotic liver. Expressions of both TIMP-1 and -2 were found to be elevated in human and rat models of liver fibrosis [10]. The resulting increase in TIMP:MMP ratio in liver may promote fibrosis by protecting deposited ECM from degradation by MMPs [11].

The renin-angiotensin system (RAS) has been shown to play a pivotal role in hepatic fibrogenesis [12]. A common observation in most of the previous studies is that liver injury is associated with an up-regulation of RAS components including angiotensinogen, renin, angiotensin converting enzyme, angiotensin (Ang) II, and Ang II type-1 (AT1) receptors [13]. The balance between ECM deposition and degradation, which depends on the relative activity of MMPs and their inhibitors, TIMPs, was also found to be affected by hepatic RAS. Following injury, AT1 receptor expression on activated HSCs is increased and these cells demonstrate increased responsiveness to Ang II compared to quiescent HSCs [14]. Angiotensin II has been shown to provoke pro-fibrotic and pro-inflammatory effects on HSCs including ECM production and fibrotic markers such as $\alpha$-smooth muscle actin and collagen, and the expression of inflammatory cytokines and growth factors such as TGF- $\beta 1$ [12].

Peroxisome proliferator activated receptor gamma (PPAR $\gamma$ ) is a ligand-activated nuclear transcription factor that belongs to the nuclear hormone receptor superfamily. Hazra et al. [15] reported that PPAR $\gamma$ depletion is associated with HSC activation, whereas increasing PPAR $\gamma$ expression induces HSC quiescence and has been found to inhibit activation markers such as $\alpha$-smooth muscle actin and collagen. Moreover, PPARy receptors were found to have anti-proliferative and anti-fibrotic effects on activated HSCs as well as inducing HSCs apoptosis through a mechanism involving an extrinsic apoptosis pathway [16].

Previous studies have shown that telmisartan (TELM) is distinguished from other members of AT1 receptor blockers by its partial agonistic activity on PPAR $\gamma$ receptors, which was previously reported to have anti-inflammatory and anti-oxidant properties $[17,18]$. Accordingly, the present study has been focused on investigating the potential effect of a drug with combined effects such as TELM, an AT1 receptor blocker and a PPARy activator, either alone or combined with PZQ, on S. mansoni-induced liver fibrosis in mice.

\section{Methods}

\section{Animals}

Swiss male albino mice of CD-1 strain, weighing 18-20 g each, were provided by the Schistosome Biology Supply Center (SBSC), Theodor Bilharz Research Institute (TBRI), Giza, Egypt. They were fed on a standard diet with free access to water at the animal house of the SBSC of TBRI. The animals were kept under standard conditions of temperature $\left(25 \pm 0.5^{\circ} \mathrm{C}\right)$, relative humidity $(55 \pm 1 \%)$ and light cycle (12 h light and $12 \mathrm{~h}$ dark). All experiments 
were conducted in accordance with the international ethical guidelines and were approved by the Ethics Committee of the TBRI.

\section{Infection}

An Egyptian strain of Schistosoma mansoni cercariae was provided by the SBSC of TBRI. Cercariae were shed from laboratory bred infected snails namely, Biomphalaria alexandrina, 25-30 days after exposure to miracidia, according to the method described by Pellegrino et al. [19]. Infection was carried out by subcutaneous injection of mice with $60 \pm 10 \mathrm{~S}$. mansoni cercariae suspended in 0.2 ml solution [20].

\section{Drugs and doses}

Praziquantel (E.I.P.I.Co. Pharmaceuticals, Cairo, Egypt) was prepared as suspension in Cremophor-El and given orally seven weeks post infection (WPI) at a dose of 500 $\mathrm{mg} / \mathrm{kg} /$ day for two consecutive days [21]. Telmisartan (Boehringer, Ingelheim, Germany) was given orally at a dose of $10 \mathrm{mg} / \mathrm{kg} /$ day [22] for five weeks. In accordance with the experimental design, it was started at either five or ten WPI.

\section{Experimental design}

Two sets of experiments were performed. In the first set, TELM treatment was initiated five WPI and in the second set, it was started ten WPI. In each set, infected mice were randomly allocated to the following four groups, each consisting of ten mice:

\section{Group I (infected control)}

This group received only the drug vehicle, p.o.

\section{Group II (TELM-treated)}

This group received TELM for five weeks.

\section{Group III (PZQ-treated)}

This group received PZQ, seven WPI for two consecutive days.

\section{Group IV (TELM+PZQ-treated)}

This group received both TELM and PZQ as indicated in groups II and III.

For comparison, a universal group (normal non-infected), consisted of 20 mice (ten for each set) was used.

All animal groups belonging to either set of experiments, were sacrificed by decapitation at the end of TELM treatment for carrying out the selected parasitological, histopathological, morphometric, immunohistochemical, and biochemical studies.

\section{Parasitological studies}

At the $10^{\text {th }}$ and $15^{\text {th }}$ WPI, all animals were sacrificed and perfused using a Masterflex pump (Cole-Parmer Instrument Company, USA). Worms recovered from the hepatic and mesenteric compartments were collected and counted. The anti-schistosomal effect of the drug was assessed parasitologically by assessing the $S$. mansoni hepatomesenteric worm load [23], and the oogram pattern to determine the percentage of the different egg developmental stages in the small intestines of mice [19].

\section{Biochemical studies}

Blood samples collected from sacrificed mice were allowed to stand for $30 \mathrm{~min}$ before centrifugation at $3000 \mathrm{rpm}$, for $15 \mathrm{~min}$. Sera were then separated and stored at $-80^{\circ} \mathrm{C}$ for further estimation of:

\section{Alanine transaminase (ALT) and aspartate transaminase (AST) enzyme activities}

Serum levels of ALT and AST were estimated using the available commercial kits (Roche Diagnostics, Germany).

\section{TGF- $\beta 1$}

Serum TGF- $\beta 1$ was detected using an enzyme-linked immunosorbent assay (ELISA) kit (R\&D Systems, USA) in accordance with the manufacturer's instructions.

\section{Histopathological studies}

Livers were excised from sacrificed mice, immediately fixed in $10 \%$ formalin solution and embedded in paraffin. Histological sections were processed and stained with hematoxylin and eosin $(H \& E)$ to examine the histopathological changes and with Masson's Trichome to measure the mean granuloma diameter $(\mu \mathrm{m})$ using an ocular micrometer (Zeiss, Germany), according to the method described by von Lichtenberg [24].

\section{Morphometric Studies}

Hepatic sections, $20 \mu \mathrm{m}$ in thickness, were prepared and stained with sirius red for the quantitation of the collagen content using the computer-controlled Image Analysis System (Leica, USA). Image analysis was performed using the computer software program KS 200.

The sectional area of the red stained fibrous tissue of the examined specimen was measured in squared microns in five consecutive microscopic fields, at X125 magnification to yield the fibrotic area $\left(\mu \mathrm{m}^{2}\right)$. Fibrotic area relative to the total area (\%) was then calculated as described by Coutinho et al. [25]. For each group, the results of all fibrotic areas $\left(\mu \mathrm{m}^{2}\right)$ and fibrotic areas (\%) were then averaged. 


\section{Immunohistochemical studies}

Hepatic sections, $4 \mu \mathrm{m}$ in thickness, were mounted on glass slides pre-treated with 3-amino propyl-triethoxy saline (TESPA). The standard avidin-biotin immunoperoxidase technique was used [26]. Hepatic paraffin sections were dewaxed in xylene and hydrated in descending grades of ethanol. The endogenous peroxidase activity was quenched by incubation in $100 \%$ methanol with $30 \%$ hydrogen peroxide for $30 \mathrm{~min}$. Antigen retrieval was performed by placing the slides in a jar filled with $20 \mathrm{ml}$ antigen retrieval solution (Dako, Denmark) and $180 \mathrm{ml}$ distilled water in a water bath for $15 \mathrm{~min}$ of microwaves at $700 \mathrm{~W}$. Sections were incubated overnight at $4^{\circ} \mathrm{C}$ in a humid chamber with primary antibodies against MMP-2 and TIMP-2 (Santa Cruz Biotechnology, Santa Cruz, CA., USA). The antibodies were diluted $1: 100,1: 100$, respectively, in phosphate buffered saline (PBS). After rinsing in PBS, the sections were incubated at room temperature for $30 \mathrm{~min}$ with biotinylated secondary anti-mouse antibody (DAKO, Denmark) and after a further wash in PBS, the slides were incubated with an avidin-biotin complex horseradish peroxidase solution (DAKO, Denmark) for another $30 \mathrm{~min}$. Slides were then washed with PBS for $5 \mathrm{~min}$. After 10 minutes incubation, the peroxidase reaction was developed using $0.01 \%$ hydrogen peroxide in $0.05 \%$ diaminobenzidine tetrahydrochloride (DAB). Sections were counterstained with Mayer's hematoxylin and dehydrated in ascending grades of ethanol prior to mounting. Liver sections, with the primary antibody replaced by PBS, served as negative controls, while colonic cancer sections served as MMP-2 and TIMP-2 positive controls. Immunostaining interpretation of either MMP-2 or TIMP-2 was carried out according to the method described by Sinicrope et al. [27]. Liver sections were examined using a light microscope (Zeiss, Germany). The number of positively stained cells with the highest expression recorded within ten successive fields (X400) was counted per section/animal in a semiquantitative way for both markers and their mean was calculated. For each group, the mean percentages were then averaged. Zero percentage was given to unstained sections.

\section{Statistical analysis}

All values are presented as means \pm S.E.M. Mean data from each study group were compared by one-way analysis of variance (one-way ANOVA). Chi-square test was used for percent positivity. $\mathrm{P}$ values less than 0.05 were considered to be statistically significant.

\section{Results}

\section{Parasitological studies}

At the $10^{\text {th }}$ and $15^{\text {th }}$ WPI, treatment with TELM alone and combined with PZQ failed to cause any significant changes in either the hepatomesenteric worm load or the oogram pattern, as compared to the infected control and PZQ-treated groups, respectively. However, PZQ treatment caused significant reduction in the hepatomesentric worm load; by 91.13 and $94.99 \%$, at the $10^{\text {th }}$ and $15^{\text {th }}$ WPI, respectively, as compared to the infected control groups. Furthermore, at the $10^{\text {th }}$ WPI, PZQ caused 100 and 90.68\% reductions in both immature and mature egg counts, respectively, as well as a 13.22-fold increase in dead eggs, as compared to the infected control group. At the $15^{\text {th }}$ WPI, treatment with PZQ showed 100 and $97.27 \%$ reductions in immature and mature egg counts, respectively, in addition to a 5.07-fold increase in the dead egg count, compared to the infected control group (Table 1).

\section{Biochemical studies}

At the $10^{\text {th }}$ and $15^{\text {th }}$ WPI, the serum TGF- $\beta 1$ measured in the infected control groups revealed 2.62- and 4.04-fold

Table 1 Effects of 5 weeks treatment with telmisartan (TELM) given either alone or combined with praziquantel (PZQ) on hepatomesenteric worm load and oogram pattern (\% egg developmental stages) of mice infected with Schistosoma mansoni and sacrificed at the $10^{\text {th }}$ (set 1 ) and $15^{\text {th }}$ (set 2 ) weeks post infection

\begin{tabular}{|c|c|c|c|c|c|c|c|c|c|}
\hline & & \multicolumn{4}{|l|}{ Set 1} & \multicolumn{4}{|l|}{ Set 2} \\
\hline & & $\begin{array}{l}\text { Infected } \\
\text { control }\end{array}$ & $\begin{array}{l}\text { TELM- } \\
\text { treated }\end{array}$ & $\begin{array}{l}\text { PZQ- } \\
\text { treated }\end{array}$ & $\begin{array}{l}\text { TELM+PZQ- } \\
\text { treated }\end{array}$ & $\begin{array}{l}\text { Infected } \\
\text { control }\end{array}$ & $\begin{array}{l}\text { TELM- } \\
\text { treated }\end{array}$ & $\begin{array}{l}\text { PZQ- } \\
\text { treated }\end{array}$ & $\begin{array}{l}\text { TELM+PZQ- } \\
\text { treated }\end{array}$ \\
\hline \multirow{4}{*}{$\begin{array}{l}\text { Hepatomesenteric } \\
\text { worm load }\end{array}$} & Male & $5.25 \pm 0.12$ & $5.75 \pm 0.51$ & $1.17 \pm 0.08^{* @}$ & $0.72 \pm 0.03^{* @}$ & $3.86 \pm 0.28$ & $4.56 \pm 0.06$ & $0.63 \pm 0.03^{*} @$ & $1.10 \pm 0.09^{*} @$ \\
\hline & Female & $1.75 \pm 0.13$ & $1.88 \pm 0.04$ & $0.17 \pm 0.01^{* @}$ & $0.14 \pm 0.01$ *@ & $1.86 \pm 0.11$ & $1.67 \pm 0.13$ & $0.00 \pm 0.00^{*} @$ & $0.00 \pm 0.00^{* @}$ \\
\hline & Couple & $4.00 \pm 0.41$ & $3.25 \pm 0.37$ & $0.00 \pm 0.00^{* @}$ & $0.00 \pm 0.00^{* @}$ & $3.72 \pm 0.08$ & $3.56 \pm 0.18$ & $0.00 \pm 0.00^{*} @$ & $0.00 \pm 0.00^{* @}$ \\
\hline & Total & $15.00 \pm 1.08$ & $14.25 \pm 0.88$ & $1.33 \pm 0.12^{* @}$ & $0.86 \pm 0.03^{* @}$ & $12.57 \pm 0.65$ & $12.56 \pm 0.41$ & $0.63 \pm 0.03^{* @}$ & $1.10 \pm 0.08^{*} @$ \\
\hline \multirow{3}{*}{$\begin{array}{l}\% \text { Egg developmental } \\
\text { stages }\end{array}$} & Immature & $48.00 \pm 2.00$ & $52.13 \pm 0.74$ & $0.00 \pm 0.00^{* @}$ & $0.00 \pm 0.00^{* @}$ & $40.57 \pm 0.61$ & $38.67 \pm 1.29$ & $0.00 \pm 0.00^{*} @$ & $0.00 \pm 0.00^{* @}$ \\
\hline & Mature & $44.75 \pm 1.93$ & $41.00 \pm 0.54$ & $4.17 \pm 2.00^{* @}$ & $3.29 \pm 0.01 * @$ & $36.57 \pm 1.11$ & $35.22 \pm 1.73$ & $1.00 \pm 0.05^{* @}$ & $0.70 \pm 0.02^{* @}$ \\
\hline & Dead & $7.25 \pm 0.02$ & $6.88 \pm 0.48$ & $95.83 \pm 2.01^{* @}$ & $96.72 \pm 0.72^{* @}$ & $19.58 \pm 1.56$ & $20.33 \pm 0.67$ & $99.13 \pm 0.44^{*}$ & $98.60 \pm 0.65^{* @}$ \\
\hline
\end{tabular}

Mice were infected with $60 \pm 10$ cercariae/mouse, injected subcutaneously. Telmisartan (TELM; $10 \mathrm{mg} / \mathrm{kg} / \mathrm{day}$, p.o.) was given at the $5^{\text {th }}$ (set 1 ) and $10^{\text {th }}$ (set 2 ) weeks post infection for 5 weeks. Praziquantel (PZQ; $500 \mathrm{mg} / \mathrm{kg} /$ day, p.o.) was given at the $7^{\text {th }}$ week post infection for 2 consecutive days. Animals were sacrificed at the end of TELM treatment. Data are represented as mean \pm S.E.M. $(n=8-10)$. Significant difference $(P<0.05) *$ versus infected control group and ${ }^{@}$ versus TELM-treated group. 


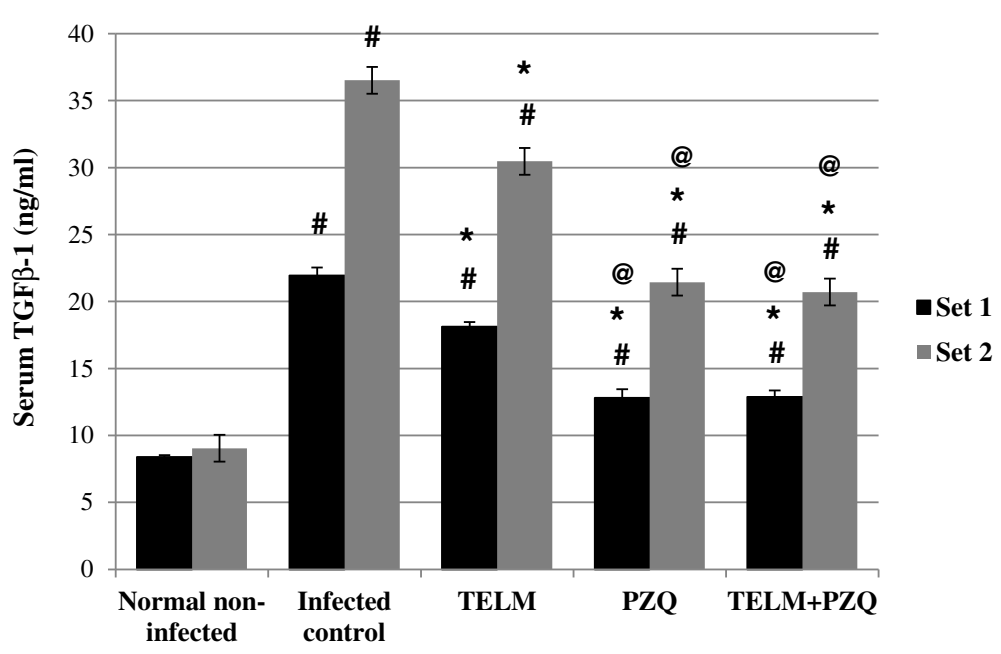

Figure 1 Effect of telmisartan (TELM; $10 \mathrm{mg} / \mathrm{kg} /$ day, for 5 weeks), praziquantel (PZQ; $500 \mathrm{mg} / \mathrm{kg} /$ day, for 2 consecutive days), and their combination on the serum levels of transforming growth factor $\beta 1$ (TGF- $\beta 1$ ) in $\mathrm{ng} / \mathrm{ml}$ of Schistosma mansoni-infected mice sacrificed at the $10^{\text {th }}$ (set 1 ) and $15^{\text {th }}$ (set 2 ) weeks post infection. All values are mean \pm S.E.M. Significantly different $(P<0.05){ }^{\#}$ versus normal non-infected group, * versus infected control group and ${ }^{@}$ versus TELM-treated group.

increases, respectively, compared to the normal noninfected groups. Moreover, the S. mansoni infection caused elevations in serum levels of ALT and AST by 1.6- and 2.33 -fold at the $10^{\text {th }}$ WPI, and by 2.01- and 2.18- fold at the $15^{\text {th }}$ WPI, respectively, compared to the normal noninfected groups. TELM- and PZQ-treated groups showed significant reductions in serum TGF- $\beta 1$ by $17.37 \%$ and $41.66 \%$ at the $10^{\text {th }}$ WPI and by $16.57 \%$ and $41.29 \%$ at the $15^{\text {th }}$ WPI, respectively, compared to their corresponding infected control groups. This showed that at the first and second sets, the reductions in the serum TGF- $\beta 1$ levels observed with PZQ treatment were higher by 2.39 and
2.49 fold than that observed with TELM. Treatment with TELM combined with PZQ did not produce significant reductions in serum TGF- $\beta 1$ levels in both sets, when compared to PZQ treatment alone (Figure 1).

At the $10^{\text {th }}$ WPI, TELM- and PZQ-treated groups did not show any significant change in serum ALT and AST levels in comparison with the infected control group. Moreover, combined treatment did not affect serum ALT levels significantly, while it caused serum AST levels to decrease by $34.52 \%$, when compared to the infected control group. However, at the $15^{\text {th }}$ WPI, TELM- and PZQ-treated groups showed reductions in serum levels of

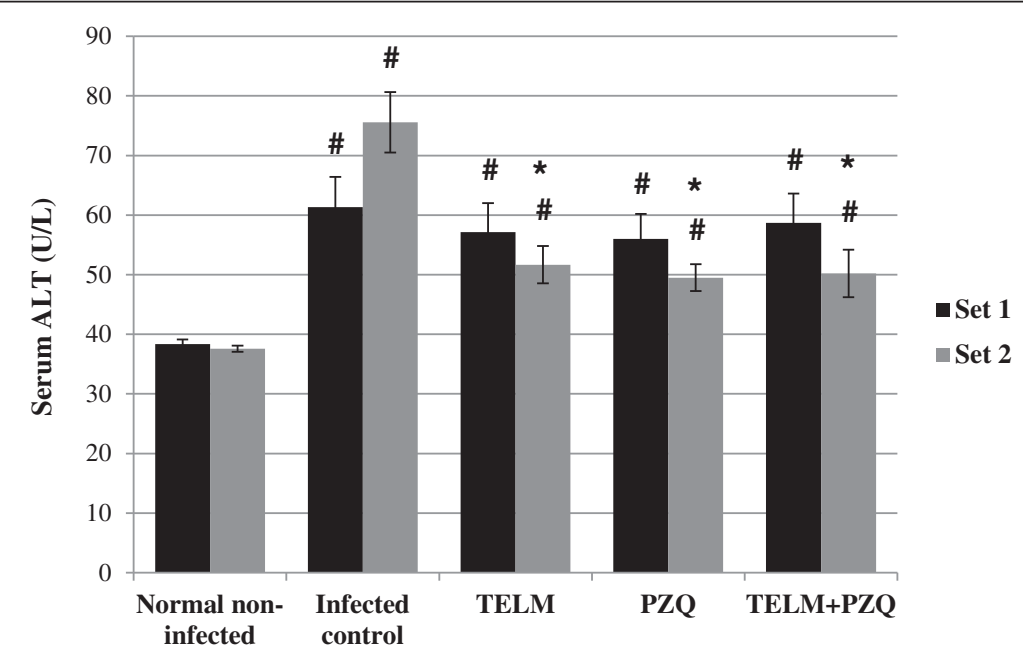

Figure 2 Effect of temisartan (TELM; $10 \mathrm{mg} / \mathrm{kg} /$ day, for 5 weeks), praziquantel (PZQ; $500 \mathrm{mg} / \mathrm{kg} /$ day, for 2 consecutive days), and their combination on the serum levels of alanine transaminase (ALT) in U/L of Schistosma mansoni-infected mice sacrificed at the $10^{\text {th }}$ (set 1 ) and $15^{\text {th }}$ (set 2 ) weeks post infection. All values are mean \pm S.E.M. Significantly different $(P<0.05)$ \# versus normal non-infected group and * versus infected control group. 


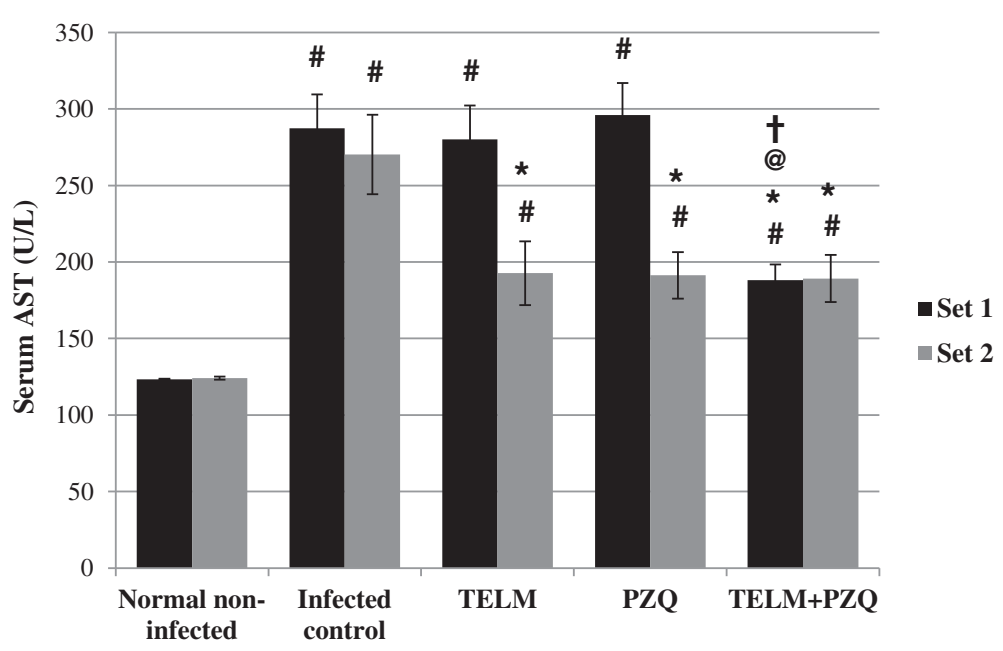

Figure 3 Effect of telmisartan (TELM; $10 \mathrm{mg} / \mathrm{kg} /$ day, for 5 weeks), praziquantel (PZQ; $500 \mathrm{mg} / \mathrm{kg} /$ day, for 2 consecutive days), and their combination on the serum levels of aspartate transaminase (AST) in U/L of Schistosma mansoni-infected mice sacrificed at the $10^{\text {th }}$ (set 1 ) and $15^{\text {th }}$ (set 2 ) weeks post infection. All values are mean \pm S.E.M. Significantly different $(P<0.05)^{\#}$ versus normal non-infected group, * versus infected control group, @ versus TELM-treated group, and ${ }^{\dagger}$ versus PZQ-treated group.

ALT by 31.63 and $34.49 \%$ and in AST by 28.72 and $29.24 \%$, respectively, compared to the infected control group. Moreover, treatment with PZQ combined with TELM decreased both ALT and AST serum levels by approximately $30 \%$, compared to the infected control group of the second set. It did not show any significant differences, however, when compared to the reductions observed in the corresponding TELM- and PZQ-treated groups (Figures 2 and 3 ).

\section{Morphometric studies}

As shown in Table 2, TELM- and PZQ-treated groups showed reductions in the estimated fibrotic areas by 32.78 and $70.53 \%$ at the $10^{\text {th }}$ WPI and by 43.06 and $54.75 \%$ at the $15^{\text {th }}$ WPI, respectively, compared to the corresponding infected control groups. At the $10^{\text {th }}$ WPI, the reduction in the area of fibrosis observed in the PZQ-treated group was 2.82-fold higher than that observed in the TELM-treated one. Combining TELM with PZQ did not show any significant change in the fibrotic area measured, when compared to PZQ-treated groups at both treatment periods.

\section{Histopathological studies}

At the $10^{\text {th }}$ WPI, mice infected with S. mansoni showed large fibrocellular granulomas in the hepatic parenchyma with an outer zone of inflammatory cells mainly eosinophils, neutrophils, and lymphocytes and an inner zone of fibrous tissue encircling the living bilharzial ova. The mean granuloma diameter was found to be $286.33 \pm 5.07 \mu \mathrm{m}$.

Table 2 Effects of 5 weeks treatment with telmisartan (TELM) given either alone or combined with praziquantel (PZQ) on the mean granuloma diameter $(\mu \mathrm{m})$, immunohistochemical expression of matrix metalloproteinase-2 (MMP-2) and tissue inhibitor of metalloproteinase-2 (TIMP-2) expressed as \% of positively stained cells, and fibrotic area in $\mu^{2}{ }^{2}$ and $\%$ of fibrotic area relative to the total area examined of mice infected with Schistosoma mansoni and sacrificed at the 10 $0^{\text {th }}$ (set 1 ) and $15^{\text {th }}$ (set 2$)$ weeks post infection

\begin{tabular}{|c|c|c|c|c|c|c|c|c|}
\hline & \multicolumn{4}{|l|}{ Set 1} & \multicolumn{4}{|l|}{ Set 2} \\
\hline & $\begin{array}{l}\text { Infected } \\
\text { control }\end{array}$ & $\begin{array}{l}\text { TELM- } \\
\text { treated }\end{array}$ & $\begin{array}{l}\text { PZQ- } \\
\text { treated }\end{array}$ & $\begin{array}{l}\text { TELM+PZQ- } \\
\text { treated }\end{array}$ & $\begin{array}{l}\text { Infected } \\
\text { control }\end{array}$ & $\begin{array}{l}\text { TELM- } \\
\text { treated }\end{array}$ & $\begin{array}{l}\text { PZQ- } \\
\text { treated }\end{array}$ & $\begin{array}{l}\text { TELM+PZQ- } \\
\text { treated }\end{array}$ \\
\hline $\begin{array}{l}\text { Mean granuloma } \\
\text { diameter }(\mu \mathrm{m})\end{array}$ & $286.33 \pm 5.07$ & $240.10 \pm 11.41^{*}$ & $228.17 \pm 6.87^{*}$ & $234.72 \pm 5.54^{*}$ & $236.72 \pm 8.04$ & $171.3 \pm 5.09^{*}$ & $158.25 \pm 7.38^{*}$ & $165.30 \pm 5.01^{*}$ \\
\hline MMP-2 (\%) & $38.75 \pm 3.07$ & $40.75 \pm 0.39$ & $37.1 \pm 2.89$ & $37.18 \pm 2.91$ & $9.29 \pm 0.07$ & $39.45 \pm 3.27^{*}$ & $10.38 \pm 0.20^{@}$ & $37.00 \pm 3.61^{*}$ \\
\hline TIMP-2 (\%) & $24.75 \pm 1.70$ & $5.75 \pm 0.96^{*}$ & $13.33 \pm 1.12^{* @}$ & $6.38 \pm 0.49^{* @}$ & $34.14 \pm 2.89$ & $7.78 \pm 0.53^{*}$ & $32.88 \pm 3.05^{@}$ & $8.58 \pm 0.81^{* \dagger}$ \\
\hline Fibrotic area $\left(\mu \mathrm{m}^{2}\right)$ & $20.10 \pm 1.23$ & $13.51 \pm 0.48^{*}$ & $5.92 \pm 0.67^{* @}$ & $5.59 \pm 0.71 * @$ & $12.75 \pm 1.01$ & $7.26 \pm 0.56^{*}$ & $5.77 \pm 0.58^{*}$ & $5.82 \pm 0.88^{*}$ \\
\hline Fibrotic area (\%) & $7.36 \pm 0.17$ & $4.94 \pm 0.29^{*}$ & $2.25 \pm 0.26^{* @}$ & $2.14 \pm 0.27^{* @}$ & $4.84 \pm 0.38$ & $2.76 \pm 0.21^{*}$ & $2.20 \pm 0.21^{*}$ & $2.22 \pm 0.32^{*}$ \\
\hline
\end{tabular}

Mice were infected with $60 \pm 10$ cercariae/mouse, injected subcutaneously. Telmisartan (TELM; $10 \mathrm{mg} / \mathrm{kg} /$ day, p.o.) was given at the $5^{\text {th }}$ (set 1 ) and $10^{\text {th }}$ (set 2 ) weeks post infection for 5 weeks. Praziquantel (PZQ; $500 \mathrm{mg} / \mathrm{kg} / \mathrm{day}$, p.o.) was given at the $7^{\text {th }}$ week post infection for 2 consecutive days. Animals were sacrificed at the end of TELM treatment. Data are represented as mean \pm S.E.M $(n=8-10)$. Significant difference $(P<0.05) *$ versus infected control group, ${ }^{\circledR}$ versus TELM-treated group, and ${ }^{\dagger}$ versus PZQ-treated group. 
(a)

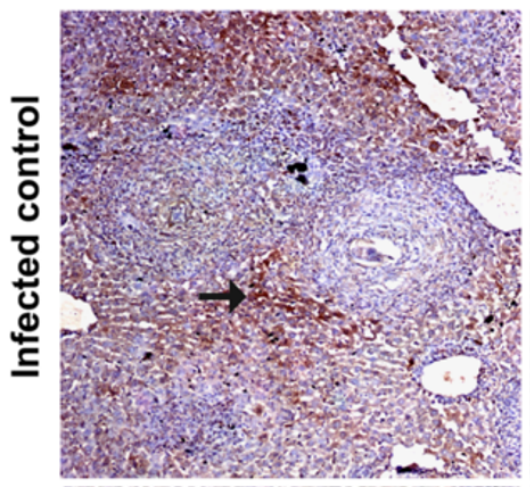

(b)
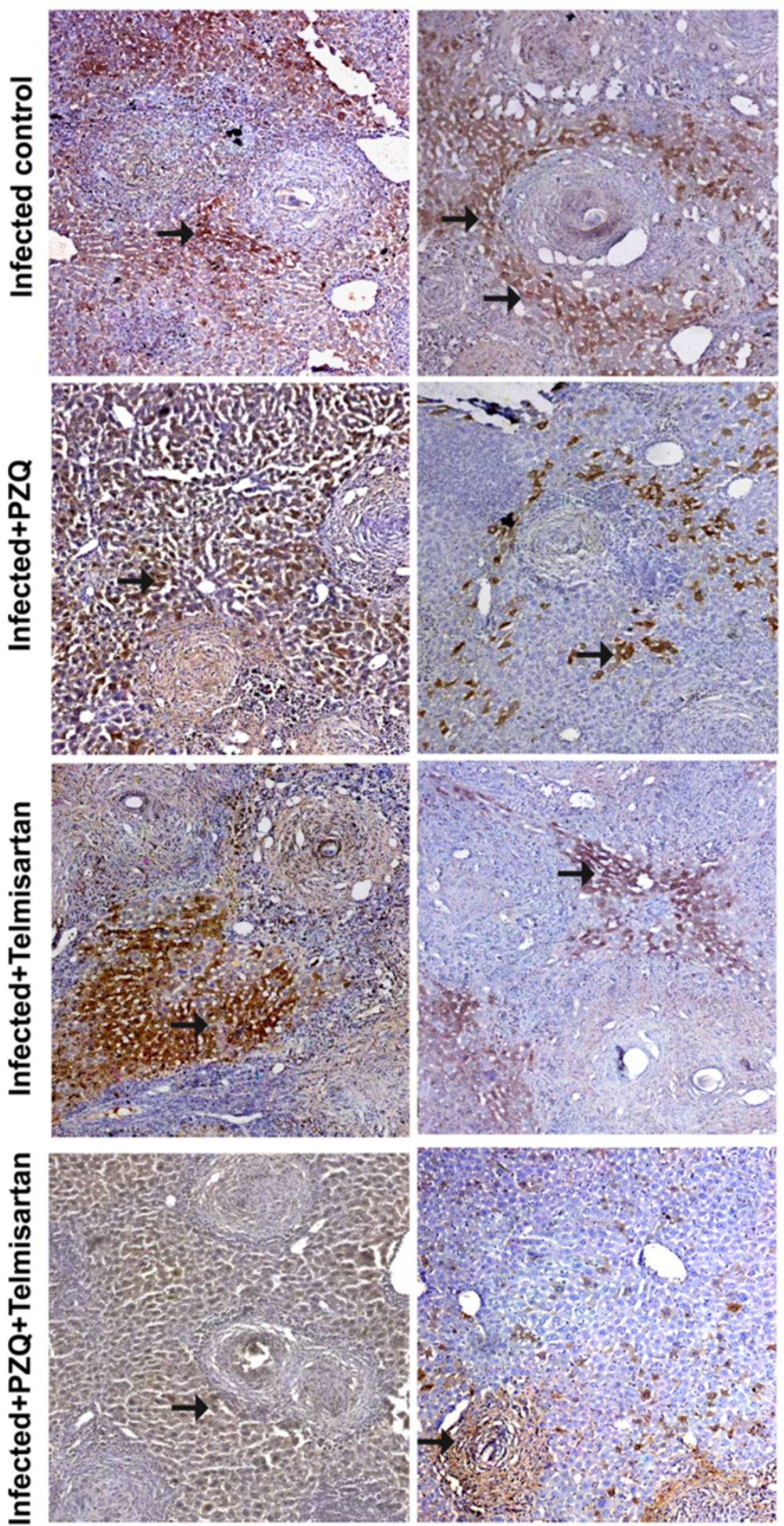

Figure 4 (See legend on next page.) 
(See figure on previous page.)

Figure 4 Immunostain for matrix metalloproteinase-2 (MMP-2; a) and tissue inhibitor of metalloproteinase-2 (TIMP-2; b) antibodies (DAB, X200) of infected control liver sections of mice sacrificed at the $10^{\text {th }}$ week post infection showing moderate and mild positively stained hepatocytes and granuloma (fibroblast and inflammatory cells; arrows), respectively. Sections taken from livers of mice treated with PZQ (500 mg/kg/day, p.o., for 2 consecutive days) showing moderate (a) and mild (b) positively stained hepatocytes, and granuloma cells (arrows). Sections taken from livers of mice treated with telmisartan (10 mg/kg/day, p.o., for 5 weeks) showing moderate (a) and mild (b) positively stained hepatocytes, and granuloma cells (arrows). Sections taken from livers of mice treated with PZQ combined with telmisartan showing moderate (a) and mild (b) positively stained hepatocytes and granuloma cells (arrows).

On the other hand, mice sacrificed at the $15^{\text {th }}$ WPI showed more granulomas deposited in the hepatic parenchyma with more dense fibrous tissue and a decrease in the inflammatory outer zone where the mean granuloma diameter was found to be $236.72 \pm 8.04 \mu \mathrm{m}$ (Table 2).

Telmisartan treatment showed a regression of the granulomatous inflammatory reaction resulting in a decrease in the mean diameter of the fibrocellular granuloma at the $10^{\text {th }}$ and $15^{\text {th }}$ WPI by 16.15 and $27.64 \%$, respectively, compared to the infected control groups (Table 2).

Treatment with PZQ showed fibrocellular granulomas formed of degenerated ova surrounded by giant cells, pigmented macrophages, lymphocytes, plasma cells, and fibrous tissue. Moreover, a decrease in the mean granuloma diameter was observed in the PZQ-treated groups at the $10^{\text {th }}$ and $15^{\text {th }}$ WPI by 20.31 and $33.15 \%$, respectively, as compared to the infected control groups (Table 2).

Combining PZQ with TELM did not produce any significant change in the mean granuloma diameter compared to either TELM- or PZQ-treated groups at both treatment periods (Table 2).

\section{Immunohistochemical studies}

As can be seen in Figure 4, treatment with TELM started at the $10^{\text {th }}$ WPI failed to show any significant change in MMP-2 hepatic expression, as compared to the infected control group. However, it caused a $76.77 \%$ reduction in TIMP-2 expression, compared to the infected control group. PZQ treatment gave a similar pattern to that of TELM. Thus, the drug did not significantly affect MMP-2 expression, as compared to the infected control group. Meanwhile, a $46.14 \%$ reduction in TIMP-2 expression was observed in the PZQ-treated group, as compared to the infected control group. Treatment with PZQ combined with TELM failed to cause any significant change in MMP-2 expression, compared to the TELM- and PZQ-treated groups, as well as TIMP-2 expression, compared to the TELM-treated group (Table 2).

At the $15^{\text {th }}$ WPI, treatment with TELM showed a 4.25-fold increase in MMP-2 expression and a reduction in TIMP-2 expression by $77.21 \%$, compared to the infected control group. However, PZQ-treated group failed to show any significant change in the expression of either MMP-2 or TIMP-2, as compared to the infected control group. Administration of $\mathrm{PZQ}$ in combination with TELM caused no significant change in either MMP-2 or TIMP-2 expression, as compared to TELM-treated group (Table 2; Figure 5).

\section{Discussion}

Hepatic schistosomiasis is considered to be one of the most prevalent forms of chronic liver disease in the world, resulting in morbidity due to complications of liver fibrosis. However, there are few medicines or means available to control and treat fibrosis resulting from schistosomiasis [28]. The immunological response to oviposition in host tissue, especially the liver, which leads eventually to hepatic fibrosis, is considered to be a direct consequence of the schistosomal pathology [29].

Renin angiotensin system blockers have been found to alleviate hepatic fibrogenesis in various experimental models [30-32]. Moreover, there are many studies nowadays suggesting that PPAR $\gamma$ ligands play an important role in inhibiting the progression of liver fibrosis by exerting anti-proliferative and pro-apoptotic actions on activated HSCs, the major collagen producers [16]. The present study has aimed at testing the efficacy of TELM, an AT1 receptor blocker and a PAR $\gamma$ activator, in both acute and chronic stages of liver fibrosis induced in mice by $S$. mansoni infection.

In order to assess the parasitological efficacy of the drugs being tested, both the hepatomesenteric worm load and the oogram pattern were used. Treatment with TELM alone failed to improve any of these parameters in infected mice. This could be attributed to the absence of any toxic effect exerted by TELM on either the eggs trapped in the tissues or the intravascular worms. On the other hand, the reductions in the hepatomesenteric worm load as well as viable egg (mature and immature) percentages observed with PZQ, either alone or combined with TELM, are in agreement with previous studies in which PZQ was used, either alone [33] or in combination with a proposed enhancer such as Nigella sativa oil [34], or dietary zinc supplement [35].

Mice that received TELM treatment showed significant reductions in the mean granuloma diameters as well as the 
(a) (b)
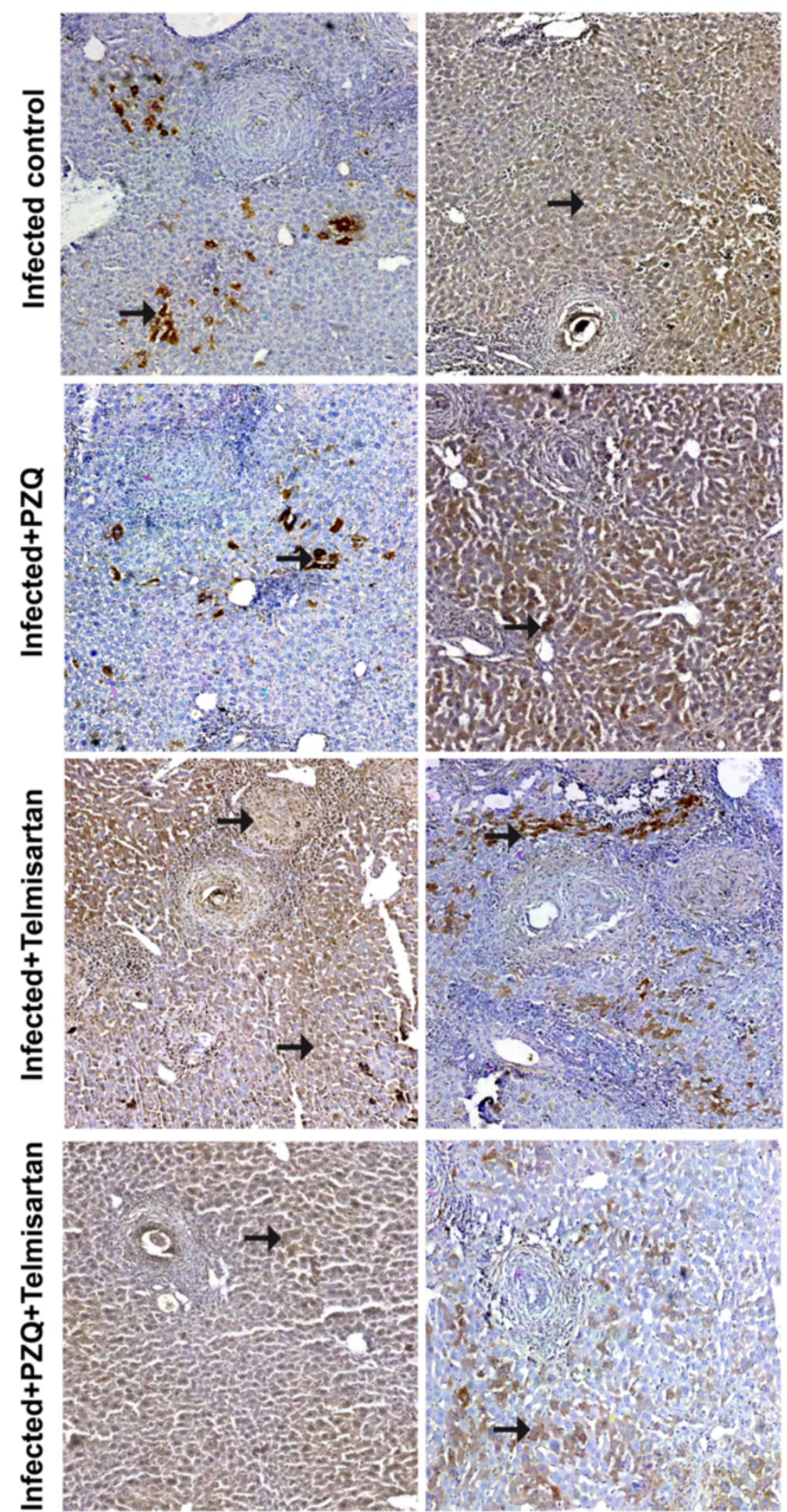

Figure $\mathbf{5}$ (See legend on next page.) 
(See figure on previous page.)

Figure 5 Immunostain for matrix metalloproteinase-2 (MMP-2; a) and tissue inhibitor of metalloproteinase-2 (TIMP-2; b) antibodies (DAB, X200) of infected control liver sections of mice sacrificed at the $15^{\text {th }}$ week post infection showing mild and moderate positively stained hepatocytes and granuloma (fibroblast and inflammatory cells; arrows), respectively. Sections taken from livers of mice treated with PZQ $(500 \mathrm{mg} / \mathrm{kg} /$ day, p.o., for 2 consecutive days) showing mild (a) and moderate (b) positively stained hepatocytes, and granuloma cells (arrows). Sections taken from livers of mice treated with telmisartan ( $10 \mathrm{mg} / \mathrm{kg} / \mathrm{day}$, p.o., for 5 weeks) showing moderate (a) and mild (b) positively stained hepatocytes, and granuloma cells (arrows). Sections taken from livers of mice treated with PZQ combined with telmisartan showing moderate (a) and mild (b) positively stained hepatocytes and granuloma cells (arrows).

estimated fibrotic areas in both sets. These results are in accordance with the results obtained by El-Lakkany et al. [36] who showed that losartan, an AT1 receptor blocker, resulted in some healing of the granulomatous hepatic lesions in $S$. mansoni-infected mice as could be observed from a reduction in the mean granuloma diameter. The authors suggested an anti-inflammatory pathway through which the drug might have suppressed the immune-mediated reaction to oviposition. It was also found that inhibition of Ang II produced changes in the mechanisms of oxidative stress, especially at the mitochondrial level, indicating an anti-inflammatory effect [37]. Furthermore, the in vitro finding that AT1 receptors are expressed on activated human HSCs and are, thus, likely to be increased in number as stellate cells proliferate, and that the binding of Ang II to these receptors induces contraction and proliferation of these cells [14], provides evidence for a potential pathway through which AT1 receptor blockers might alleviate hepatic fibrosis. In addition, Hazra et al. [15] reported that PPAR $\gamma$ depletion is associated with HSC activation, whereas HSC quiescence is induced by increasing PPAR $\gamma$ expression, which has been found to inhibit activation markers such as $\alpha$-smooth muscle actin and collagen. Accordingly, we can conclude that the reduction in the mean granuloma diameter and the fibrotic area, as measures of the degree of fibrosis, caused by TELM treatment, could be attributed to the anti-inflammatory activity as well as its inhibitory effects on HSCs activation, being an AT1 receptor blocker and a PPAR $\gamma$ activator.

The reduction in the granuloma size, following PZQ treatment, has been previously reported by Botros et al. [38]. The authors noted a reduction in T-helper cells in the bilharzial granuloma and stated that the granuloma size reduction after PZQ treatment could be the result of the inhibition of the inflammatory mediators released locally at the site of the granulomatous inflammation.

Collagen turnover and ECM remodeling that occur during various physiological and pathological processes including tissue repair, wound healing, fibrosis, and tumor invasion are largely dependent on the regulation of MMP and TIMP activities [39]. In the current study, liver sections of $S$. mansoni-infected mice belonging to both sets, showed moderate expressions of both MMP-2 and TIMP-2. This is because the expression of both genes is up-regulated and mainly expressed by HSCs during fibrogenesis. However, during liver fibrosis resolution, as TIMP expression declines, the persistence of MMP-2 may permit collagen degradation [40]. It was found that MMP-2 expression increased and remained elevated during experimental fibrogenesis induced by carbon tetrachloride $\left(\mathrm{CCl}_{4}\right)$ [41]. Yet, high levels of TIMP-2 in the fibrotic liver were capable of inhibiting active MMP-2 [42].

TELM alone increased MMP-2 expression in the second set, and decreased TIMP-2 expression significantly in both sets. The study of Cheng et al. [39] showed that activating PPAR $\gamma$ by curcumin treatment increased MMP-2 activity significantly and that this effect was weakened by the specific PPAR $\gamma$ antagonist. In addition, $\mathrm{Yu}$ et al. [16] demonstrated that PPAR $\gamma$ activation significantly reduced expression levels of TIMP-2 in liver tissue suggesting that it has dual inhibitory effects on HSC activation through inhibiting collagen production and stimulating matrix degradation. Thus, it can be concluded that the observed elevation in MMP-2 and the decline in TIMP-2 expression may have contributed to collagen degradation and a consequent decrease in granuloma diameters and fibrotic areas following TELM treatment.

PZQ treatment alone did not show significant elevation in MMP-2 expression compared to infected controls of both sets. Meanwhile, it caused a reduction in TIMP-2 expression at the $15^{\text {th }}$ WPI while no change was observed at the $10^{\text {th }}$ WPI. These results are in agreement with the study of Singh et al. [43], who showed that PZQ treatment did not cause significant changes in MMP-2 expression in S. mansoni-infected mice, whereas TIMP-2 expression showed little or no change.

Previous studies have shown that in the evolution of the granulomatous response to the S. mansoni eggs, TGF- $\beta 1$ is produced and may modulate inflammation and hence regulate fibrogenesis $[43,44]$. In the current study, TELM caused significant reductions in serum TGF- $\beta 1$ levels in both sets. A relevant study [32] showed that olmesartan; an AT1 receptor antagonist, succeeded in reducing plasma levels of TGF- $\beta 1$ in bile duct-ligated rats. Bataller et al. [12] also showed that Ang II is a potent inducer of TGF- $\beta 1$ production in cultured HSCs 
and in vivo. The previously mentioned results suggest that there is a close relationship between Ang II and TGF- $\beta 1$. Accordingly, the current study reinforces the prevailing hypothesis that TGF- $\beta 1$ in fibrotic disease depends, at least in part, on Ang II generation. Consistent with the previous results, also is the study of Chen et al. [28] who demonstrated that PPAR $\gamma$ ligand, rosiglitazone, can reduce inflammation and liver fibrosis with Schistosoma infection by reducing TGF- $\beta 1$ expression.

Results of the current work revealed that the reductions in serum TGF- $\beta 1$ levels observed with PZQ were significantly higher than those observed with TELM. This could be attributed to the anti-helminthic activity of PZQ, which leads to the death of viable eggs and prevents their further deposition, which is considered to be the triggering stimulus for the multiple signalling pathways involved in the generation of TGF- $\beta 1$ in this model. Telmisartan, however, affects only two of these pathways i.e. Ang II and PPAR $\gamma$. The reduction in TGF- $\beta 1$ levels elicited by PZQ is consistent with the studies of Singh et al. [43]; El-Lakkany \& Nosseir [44], and El-Lakkany et al. [45] that revealed a marked drop (amounting to $70 \%$ in the first study) in the TGF- $\beta 1$ expression caused by PZQ in $S$. mansoni-infected mice.

In the current study, combined TELM and PZQ treatment generally failed to show significantly better results from using either TELM or PZQ alone, provided that the former is given at a dose of $10 \mathrm{mg} / \mathrm{kg} /$ day for 5 weeks and the latter is given early in a full curative dose $(500 \mathrm{mg} / \mathrm{kg} /$ day for 2 consecutive days) as previously mentioned. Hence, this combination did not seem to have an added benefit. This could be attributed to the reduction in egg deposition caused by early PZQ treatment, which is the injurious triggering stimulus for the activation of HSCs. Consequently, this leads to the reduction in the expression of AT1 receptors available for TELM blockade as well as less reduction in PPAR $\gamma$ receptor expression. Thus, in a combined regimen, early treatment with PZQ may have reduced the anti-fibrotic effects observed when compared to using TELM alone. However, a recent study [46] demonstrated an anti-fibrotic effect of PZQ $(300 \mathrm{mg} / \mathrm{kg}$, given twice daily for 30 days) at the $8^{\text {th }}$ and $15^{\text {th }}$ WPI in mice with advanced chronic schistosomiasis as well as in $\mathrm{CCl}_{4}$-induced liver fibrosis. Yet, further studies examining the efficacy of combining TELM to PZQ, which may require using different doses of both drugs, are recommended to support this speculation.

\section{Conclusion}

In conclusion, our study showed a significant reduction of liver fibrosis following treatment with TELM, an AT1 receptor blocker and a PPAR $\gamma$ ligand, in a murine model of hepatic fibrosis induced by S. mansoni infection. The anti-fibrotic effect of this compound could be due to down-regulation of TGF- $\beta 1$ as well as increasing the hepatic expression of MMP-2 relative to TIMP-2. Thus, its potential improvement of fibrotic markers makes the drug a particularly strong candidate for treating hepatic fibrosis. Moreover, TELM may be more efficient than other AT1 receptor blockers such as losartan or candesartan, in suppressing liver fibrosis, due to activation of PPAR $\gamma$ receptors besides AT1 receptor antagonism.

The RAS and the PPAR $\gamma$ receptors are important targets for the treatment of fibrosis. Searching for agents that can affect multiple signalling pathways involved in hepatic fibrosis is recommended. Additionally, testing the efficacy as well as the safety of prolonged PZQ treatment as an anti-fibrotic, independent of its antihelminthic activity, particularly in the late stages, is also recommended. Finally, the effectiveness of TELM as a choice for patients treated for hypertension or heart failure associated with liver affection needs further research.

\section{Competing interests}

All authors declare that they have no competing interests.

\section{Authors' contributions}

ASE and EFA conceived and designed the experiments; YMA performed the experiments and the biochemical analysis; $\mathrm{OAH}$ performed the histopathological, morphometric, and immunohistochemical studies; SSM performed the parasitological studies; ASE, OAH, EFA, and YMA analyzed the data; ASE, OAH, EFA, and YMA prepared the manuscript. All authors have read and approved the final version of the manuscript.

\section{Author details}

'Department of Pharmacology and Biochemistry, Faculty of Pharmacy, The British University in Egypt, Suez Desert Road, P.O. Box 43, El Sherouk City, Cairo 11837, Egypt. ${ }^{2}$ Department of Pharmacology, Faculty of Medicine, Cairo University, Al-Saray St., El Manial, Cairo 11956, Egypt. ${ }^{3}$ Department of Pathology, Theodor Bilharz Research Institute, Warrak El-Hadar, Imbaba, P.O. Box 30, Giza 12411, Egypt. ${ }^{4}$ Department of Parasitology, Theodor Bilharz Research Institute, Warrak El-Hadar, Imbaba, P.O. Box 30, Giza 12411, Egypt. ${ }^{5}$ Department of Pharmacology and Toxicology, Faculty of Pharmacy, Cairo University, Kasr El-Aini St., Cairo 11562, Egypt.

Received: 3 March 2013 Accepted: 17 June 2013

Published: 5 July 2013

\section{References}

1. Molyneux DH, Malecela MN: Neglected tropical diseases and the millennium development goals: why the "other diseases" matter: reality versus rhetoric. Parasit Vectors 2011, 4:234.

2. Engels D, Chitsulo L, Montresor A, Savioli L: The global epidemiological situation of schistosomiasis and new approaches to control and research. Acta Trop 2002, 82:139-146.

3. Ahmed AM, Abbas H, Mansour FA, Gasim Gl, Adam I: Schistosoma haematobium infections among schoolchildren in central Sudan one year after treatment with praziquantel. Parasit Vectors 2012, 5:108.

4. Gryseels B: Morbidity due to infection with Schistosoma mansoni: an update. Trop Geogr Med 1992, 44:189-200.

5. Mohamed-Ali Q, Elwali N, Abdelhameed A, Mergani A, Rahoud S, Elagib K, Saeed O, Abel L, Magzoub M, Dessein A: Susceptibility to periportal (Symmers) fibrosis in human schistosoma mansoni infections: evidence that intensity and duration of infection, gender, and inherited factors are critical in disease progression. J Infect Dis 1999, 180:1298-1306. 
6. Tacke F, Weiskirchen R: Update on hepatic stellate cells: pathogenic role in liver fibrosis and novel isolation techniques. Expert Rev Gastroenterol Hepatol 2012, 6:67-80.

7. Bataller R, Brenner DA: Liver fibrosis. J Clin Invest 2005, 115:209-218.

8. Arthur MJ: Matrix degradation in liver: a role in injury and repair. Hepatology 1997, 26:1069-1071.

9. Loebermann M, Sombetzki M, Langner C, Fuchsbichler A, Gumhold J, Silbert D, Riebold D, Holtfreter M, Fickert P, Nizze H, Trauner M, Reisinger EC: Imbalance of pro- and antifibrogenic genes and bile duct injury in murine Schistosoma mansoni infection-induced liver fibrosis. Trop Med Int Health 2009, 14:1418-1425.

10. Knittel T, Mehde M, Kobold D, Saile B, Dinter C, Ramadori G: Expression patterns of matrix metalloproteinases and their inhibitors in parenchymal and non-parenchymal cells of rat liver: regulation by TNF-alpha and TGF-beta1. J Hepatol 1999, 30:48-60.

11. Murphy G, Stanton H, Cowell S, Butler G, Knäuper V, Atkinson S, Gavrilovic J: Mechanisms for pro matrix metalloproteinase activation. APMIS 1999, 107:38-44.

12. Bataller $R$, Sancho-Bru $P$, Ginès $P$, Lora JM, Al-Garawi $A$, Solé $M$, Colmenero J, Nicolás JM, Jiménez W, Weich N, Gutiérrez-Ramos JC, Arroyo V, Rodés J: Activated human hepatic stellate cells express the renin-angiotensin system and synthesize angiotensin II. Gastroenterology 2003, 125:117-125.

13. Paizis G, Cooper ME, Schembri JM, Tikellis C, Burrell LM, Angus PW: Up-regulation of components of the renin-angiotensin system in the bile duct-ligated rat liver. Gastroenterology 2002, 123:1667-1676.

14. Bataller R, Ginès P, Nicolás JM, Görbig MN, Garcia-Ramallo E, Gasull X, Bosch J, Arroyo V, Rodés J: Angiotensin II induces contraction and proliferation of human hepatic stellate cells. Gastroenterology 2000, 118:1149-1156.

15. Hazra S, Xiong S, Wang J, Rippe RA, Krishna V, Chatterjee K, Tsukamoto H: Peroxisome proliferator-activated receptor gamma induces a phenotypic switch from activated to quiescent hepatic stellate cells. J Biol Chem 2004, 279:11392-11401.

16. Yu J, Zhang S, Chu ES, Go MY, Lau RH, Zhao J, Wu CW, Tong L, Zhao J, Poon TC, Sung JJ: Peroxisome proliferator-activated receptors gamma reverses hepatic nutritional fibrosis in mice and suppresses activation of hepatic stellate cells in vitro. Int J Biochem Cell Biol 2010, 42:948-957.

17. Yamagishi $\mathrm{S}$, Takeuchi M: Telmisartan is a promising cardiometabolic sartan due to its unique PPAR-gamma-inducing property. Med Hypotheses 2005, 64:476-478

18. Kobayashi N, Ohno T, Yoshida K, Fukushima H, Mamada Y, Nomura M, Hirata H, Machida Y, Shinoda M, Suzuki N, Matsuoka H: Cardioprotective mechanism of telmisartan via PPAR-gamma-eNOS pathway in dahl saltsensitive hypertensive rats. Am J Hypertens 2008, 2:576-581.

19. Pellegrino J, Oliveira CA, Faria J, Cunha AS: New approach to the screening of drugs in experimental schistosomiasis mansoni in mice. Am J Trop Med Hyg 1962, 11:201-215

20. Holanda JC, Pellegrino J, Gazzinelli G: Infection of mice with cercariae and schistosomula of Schistosoma mansoni by intravenous and subcutaneous routes. Rev Inst Med Trop Sao Paulo 1974, 16:132-134.

21. Gönnert R, Andrews P: Praziquantel, a new broad-spectrum antischistosomal agent. Z Parasitenkd 1977, 52:129-150.

22. Halici Z, Bilen H, Albayrak F, Uyanik A, Cetinkaya R, Suleyman H, Keles ON, Unal B: Does telmisartan prevent hepatic fibrosis in rats with alloxan-induced diabetes? Eur J Pharmacol 2009, 614:146-152.

23. Duvall RH, DeWitt WB: An improved perfusion technique for recovering adult schistosomes from laboratory animals. Am J Trop Med Hyg 1967, 16:483-486

24. von Lichtenberg: Host response to eggs of S. mansoni. I. Granuloma formation in the unsensitized laboratory mouse. Am J Pathol 1962, 41:711-731.

25. Coutinho EM, Barros AF, Barbosa A Jr, Oliveira SA, Silva LM, Araújo RE, Andrade ZA: Host nutritional status as a contributory factor to the remodeling of schistosomal hepatic fibrosis. Mem Inst Oswaldo Cruz 2003, 98:919-925.

26. Hsu SM, Raine L: Protein A, avidin, and biotin in immunohistochemistry. J Histochem Cytochem 1981, 29:1349-1353.

27. Sinicrope FA, Ruan SB, Cleary KR, Stephens LC, Lee JJ, Levin B: bcl-2 and p53 oncoprotein expression during colorectal tumorigenesis. Cancer Res 1995, 55:237-241.

28. Chen $\mathrm{H}, \mathrm{He}$ YW, Liu WQ, Zhang JH: Rosiglitazone prevents murine hepatic fibrosis induced by Schistosoma japonicum. World J Gastroenterol 2008 14:2905-2911
29. Cheever AW, Hoffmann KF, Wynn TA: Immunopathology of schistosomiasis mansoni in mice and men. Immunol Today 2000, 21:46-466.

30. Jonsson JR, Clouston AD, Ando Y, Kelemen LI, Horn MJ, Adamson MD, Purdie DM, Powell EE: Angiotensin-converting enzyme inhibition attenuates the progression of rat hepatic fibrosis. Gastroenterology 2001, 121:148-155.

31. Yoshiji H, Kuriyama S, Yoshii J, Ikenaka Y, Noguchi R, Nakatani T, Tsujinoue $H$, Fukui $H$ : Angiotensin-II type 1 receptor interaction is a major regulator for liver fibrosis development in rats. Hepatology 2001, 34:745-750.

32. Kurikawa N, Suga M, Kuroda S, Yamada K, Ishikawa H: An angiotensin II type 1 receptor antagonist, olmesartan medoxomil, improves experimental liver fibrosis by suppression of proliferation and collagen synthesis in activated hepatic stellate cells. Br J Pharmacol 2003, 139:1085-1094.

33. El-Fakahany AF, Abdalla KF, El-Hady HM, Abd E, Aziz SM, Afifi LM: The effect of praziquantel treatment on the liver functions, worm burden, and granuloma size using two drug regimen in murine Schistosoma mansoni infection. J Egypt Soc Parasitol 1993, 23:877-886.

34. Mahmoud MR, Zoheiry MM, Nosseir MM: Effect of combined chemotherapy and anti-inflammatory drugs on murine schistosomiasis. Arzneimittelforschung 2002, 52:294-301.

35. Helmy MM, Mahmoud SS, Fahmy ZH: Schistosoma mansoni: effect of dietary zinc supplement on egg granuloma in Swiss mice treated with praziquantel. Exp Parasitol 2009, 122:310-317.

36. El-Lakkany NM, El-Maadawy W, Ain-Shoka A, Badawy A, Hammam O, Ebeid F: Potential antifibrotic effects of AT1 receptor antagonist, losartan, and/ or praziquantel on acute and chronic experimental liver fibrosis induced by Schistosoma mansoni. Clin Exp Pharmacol Physiol 2011, 38:695-704.

37. Ferder LF, Inserra F, Basso N: Advances in our understanding of aging: role of the renin-angiotensin system. Curr Opin Pharmacol 2002, 2:189-194.

38. Botros SS, el-Badrawy N, Metwally AA, Khayyal MT: Study of some immunopharmacological properties of praziquantel in experimental schistosomiasis mansoni. Ann Trop Med Parasitol 1986, 80:189-196.

39. Cheng Y, Ping J, Xu LM: Effects of curcumin on peroxisome proliferatoractivated receptor gamma expression and nuclear translocation/ redistribution in culture-activated rat hepatic stellate cells. Chin Med J (Engl.) 2007, 120:794-801.

40. Arthur MJ: Fibrogenesis II. Metalloproteinases and their inhibitors in liver fibrosis. Am J Physiol Gastrointest Liver Physiol 2000, 279:G245-G249.

41. Zhou X, Hovell CJ, Pawley S, Hutchings MI, Arthur MJ, Iredale JP, Benyon RC: Expression of matrix metalloproteinase- 2 and -14 persists during early resolution of experimental liver fibrosis and might contribute to fibrolysis. Liver Int 2004, 24:492-501.

42. Iredale JP, Benyon RC, Pickering J, McCullen M, Northrop M, Pawley S, Hovell C, Arthur MJ: Mechanisms of spontaneous resolution of rat liver fibrosis. Hepatic stellate cell apoptosis and reduced hepatic expression of metalloproteinase inhibitors. J Clin Invest 1998, 102:538-549.

43. Singh KP, Gerard HC, Hudson AP, Boros DL: Expression of matrix metalloproteinases and their inhibitors during the resorption of schistosome egg-induced fibrosis in praziquantel-treated mice. Immunology 2004, 111:343-352.

44. El-Lakkany N, Nosseir M: Pharmacodynamics of pentoxifylline and/or praziquantel in murine schistosomiasis mansoni. APMIS 2007, 115:184-194.

45. El-Lakkany NM, Hammam OA, El-Maadawy WH, Badawy AA, Ain-Shoka AA, Ebeid FA: Anti-inflammatory/anti-fibrotic effects of the hepatoprotective silymarin and the schistosomicide praziquantel against Schistosoma mansoni-induced liver fibrosis. Parasit Vectors 2012, 5:9.

46. Liang YJ, Luo J, Yuan Q, Zheng D, Liu YP, Shi L, Zhou Y, Chen AL, Ren YY, Sun KY, Sun $Y$, Wang $Y$, Zhang ZS: New insight into the antifibrotic effects of praziquantel on mice in infection with Schistosoma japonicum. PLoS One 2011, 6:e20247.

\section{doi:10.1186/1756-3305-6-199}

Cite this article as: Attia et al:: Telmisartan, an AT1 receptor blocker and a PPAR gamma activator, alleviates liver fibrosis induced experimentally by Schistosoma mansoni infection. Parasites \& Vectors 2013 6:199. 